1 CHAPTER 10

3

EMOTIONAL LABOUR AND ITS

5

CONSEQUENCES: THE

7

MODERATING EFFECT OF

9

EMOTIONAL INTELLIGENCE

13 Catherine Prentice

ABSTRACT

This study examines the relationship between emotional labour and burnout and the moderating effect of emotional intelligence on this relationship. The survey was conducted at several tourism and hospitality organizations in Florida, USA. The results show that both acting strategies of emotional labour relate positively to burnout. Tests of moderation show that emotional intelligence reduces employee burnout. These findings contribute to the literature on emotional labour by incorporating emotional intelligence as a moderator, and provide some guidance for human resource practitioners about potentially beneficial training and recruitment activities. They also have implications for customer relationship management.

Keywords: Emotional labour; emotional intelligence; burnout; task performance and OCB

Individual Sources, Dynamics, and Expressions of Emotion 
3 The concept of emotional labour (EL) has been discussed extensively in the relevant literature, consistent with the increasing applicability of dramaturgical perspectives to customer interactions and the importance of services to the economy. It particularly applies in the case of frontline service

7 positions dealing with customers (Ashforth \& Humphrey, 1993). Defined as managing emotions through surface or deep acting by following organisa-

9 tional display rules in return for a wage, EL has been proposed as a means of enhancing task performance and as a strategy for managing service

11 encounters efficiently through appropriate acting (Hochschild, 1983). Despite its likely influence on employee task effectiveness, EL is commonly

13 acknowledged to have negative psychological effects on employees. Such effects include stress (e.g. Mann \& Cowburn, 2005), poor self-esteem (e.g.

15 Sakiyama, 2009), job dissatisfaction (Pugliesi, 1999). These negative outcomes ultimately lead to burnout (see Brotheridge \& Grandey, 2002;

17 Erickson \& Ritter, 2001; Surana \& Singh, 2009)

Burnout has been widely discussed in EL research (e.g. Brotheridge, \&

19 Grandey, 2002; Johnson \& Spector, 2007; Montgomery, Panagopolou, Wildt, \& Meenks, 2006). However, most research has concentrated on a

21 single dimension of burnout, namely emotional exhaustion. Burnout is identified as a multidimensional construct consisting of emotional exhaus-

23 tion, diminished personal accomplishment, and depersonalisation (Maslach, Schaufeli, \& Leiter, 2001). According to Maslach et al. (2001), exhaustion is

25 a necessary but insufficient condition for burnout. Emotional exhaustion is likely to lead the employee to distance him or herself emotionally and

27 cognitively from work. Depersonalisation is one means of placing distance between oneself and service recipients and distancing is an immediate

29 reaction to exhaustion; whereas diminished personal accomplishment appears to be a function of exhaustion and/or depersonalisation. The three

31 dimensions interact and neglecting any of them may lose sight of the entire phenomenon (Maslach et al., 2001). Hence, the current study includes these

33 dimensions to examine their relationships with EL.

Furthermore, since most of the relevant literature shows that EL is

35 associated with the negative effects of individual outcomes, this potentially prompts a concern about why organizations persist in implementing display

37 rules and 'encourage' employees to 'act' or perform emotional labour. If such EL related 'acting' is required for certain roles and professions, efforts

39 may be needed to minimise any detrimental effects. Researchers have suggested that understanding of the negative consequences of EL may be 
1 improved by incorporating moderators (e.g. Daus \& Ashkanasy, 2005). Johnson and Spector (2007) identified gender and autonomy as moderators

3 of EL strategies as well as personal outcomes such as emotional exhaustion and affective wellbeing. As indicated by various researchers (e.g. Ashforth \&

5 Humphrey, 1993; Daus \& Ashkanasy, 2005), EL has particular relevance for employees who interact with customers, and such encounters involve a high

7 level of emotional elements (e.g. Mattila \& Enz, 2002). Employee emotional management skills may be necessary to facilitate the EL process in order to

9 achieve enhanced results. Consistent with the forgoing discussion, the second aim of this chapter is to propose and test if emotional intelligence is a

11 potential moderator of the EL process leading to the prospect of improved outcomes. The following section formulates hypotheses for the study.

\section{HYPOTHESES FORMATION}

EL and burnout

19 Researchers generally believe that burnout is related positively to the surface acting element of the EL process but negatively related to deep acting (e.g.

21 Brotheridge \& Grandey, 2002; Grandey, 2003; Kim, 2008). Portraying emotions that are not felt (surface acting) may create emotive dissonance

23 that is akin to cognitive dissonance (Hochschild, 1983). Such dissonance may cause the labourer to feel false and hypocritical. Ultimately, such

25 dissonance can lead to personal and work-related maladjustments such as poor self-esteem, depression, cynicism and alienation from work

27 (Ashforth \& Humphrey, 1993; Fineman, 1993; Seeman, 1991). Although most EL researchers agree that deep acting is negatively associated with

29 burnout, the opposite view is held by some others (e.g. Ashforth \& Humphrey, 1993; Mikolajczak, Menil, \& Luminet, 2007). Such different

31 conclusions may be explained by the fact that the research has been conducted in a variety of contexts. In the case of demanding jobs such as

33 frontline positions, or so-called job-focused emotional labour where the employee has a low level control, both types of acting can lead to negative

35 outcomes (Brotheridge \& Grandey, 2002; Pugliesi, 1999).

Ashforth and Humphrey (1993) have argued that EL is a double-edged

37 sword when managing encounters with highly demanding customers. Either type of acting may have negative psychological consequences. Surface acting

39 may cause emotive dissonance and lead to work-related maladjustment; and deep acting may distort employee reactions and impair one's sense of the 
1 authentic self (Ashforth \& Humphrey, 1993). This may ultimately lead to self-alienation and an impaired capacity to recognize or even experience genuine emotions. The reworking of authentic emotions (deep acting) has been found to be positively associated with psychological dysfunctions and overall stress (Parkinson, 1991; Rutter \& Fielding, 1988). Such stress may eventually lead to burnout. Indeed, Mikolajczak et al.'s (2007) study

7 demonstrated a positive relationship between deep acting and three dimensions of burnout. On the basis of the above discussion, the following

9 hypothesis is proposed:

11 H1. Within the EL process, surface and deep acting by frontline employees will positively influence three dimensions of burnout, namely emotional exhaustion, diminished personal accomplishment and depersonalisation.

\section{Emotional intelligence as a moderator of EL}

The concept of emotional intelligence appeared within the professional and

19 academic domains of psychology during the 1990s, and taps into much of the performance variance that was inadequately explained by traditional

21 intelligence (IQ). The construct has particular relevance in the case of service personnel and their job-related outcomes because their employment

23 involves substantial interpersonal interactions that require emotional work (Ashforth \& Humphrey, 1993; Ashkanasy \& Daus, 2005). Emotional

25 intelligence has been defined as the ability to perceive, respond and manipulate emotional information without necessarily understanding it and the

27 ability to understand and manage emotions without necessarily perceiving feelings well or experiencing them fully (Mayer \& Salovey, 1997). Mayer,

29 Salovey, Caruso and Sitarenios (2001) have classified these abilities into four hierarchical branches. The first branch is emotional perception. It involves

31 the ability to identify and express emotions, and to discriminate various expressions of feelings. Emotional assimilation, which is the second branch,

33 includes emotion-prioritised thinking by directing attention to important information. Emotional mood swings may, for example change an indivi-

35 dual's perspective from optimistic to pessimistic, whereas happiness facilitates inductive reasoning and creativity. The third branch, emotional

37 understanding, involves the ability to label and recognise emotions and emotional transitions, for instance, the transition from anger to satisfaction,

39 and the ability to understand complex feelings. The fourth branch, emotions management, includes the ability to stay open to feelings, to engage or 
1 detach from an emotion, to monitor emotions and to manage emotions in oneself and others by moderating negative emotions and enhancing 3 pleasant ones.

Although emotional intelligence is widely acknowledged in the literature 5 as a valid predictor of various criterion variables, it has also been popularised as a moderator. For instance, Jordan, Ashkanasy and Hartel

7 (2003) have proposed it as a moderator of emotional and behavioural reactions to job insecurity. Emotional intelligence can also facilitate coping

9 with workplace-related stress and moderate the relationship between conscientiousness and performance (Ashkanasy, Jordan, \& Ashton-James,

11 2003; Douglas, Frink \& Ferris, 2004). In the context of services, Gabbott, Tsarenko, and Mok (2011) found that emotional intelligence can shape

13 customer reactions towards service failure. Although few studies have investigated the moderating effect of emotional intelligence in the EL

15 process, it has been proposed as a moderating factor on individual outcomes in the case of the two EL-related acting strategies (Grandey, 2003). Salami

17 (2007) found that emotional intelligence successfully moderated the relationship between surface acting and OCBs and additional empirical

19 research is warranted within the EL literature to extend this finding.

From its conceptualisation into four hierarchical branches, emotional

21 intelligence may be capable of adjusting the EL process. For example, the first branch may influence surface acting (simulating emotions that are not

23 actually felt). The may be explained as follows. Emotions can only be simulated effectively in circumstances where the perception is accurate,

25 thereby allowing the simulation to fit the context. A nurse may for example simulate sympathy for a patient who has deep concerns about his

27 or her health. In this circumstance the process of simulation is dependent on the nurse possessing the required perception of the patient's concerns.

29 The fourth branch can facilitate deep acting (attempts to experience or feel the emotions that one wishes to display). Mayer et al. (2001) indicated

31 that the four branches function hierarchically. The perception of emotions acts as both the most basic branch and as a precursor to the other three.

33 Since it occupies the top branch, emotional management may be viewed as the most complex. Once a perception has been acquired, emotions

35 may be transferred to conscious or unconscious thought to facilitate behaviours (Levine, 1997, Mayer et al., 2001). Hence, a hypothesis is

37 made as follows:

39 Hypothesis 2. Emotional intelligence will moderate the effects of surface and deep acting in the EL process on burnout. 


\section{METHOD}

\section{Procedure}

5 A self-report questionnaire was developed to collect information using a paper-pencil test. The questions investigated EL, burnout, emotional

7 intelligence, task performance and OCB. The written instructions provided respondents with an assurance of anonymity. The survey packets included a

9 cover letter introducing the research and explaining its significance and objectives. An expression of thanks was also provided to prospective

11 respondents along with a consent form, a questionnaire, and a pre-paid envelope. Detailed instructions were included to stimulate and guide

13 participation. Research assistants distributed the questionnaire to prospective respondents who were required to respond within two months of receipt.

\section{Participants}

The respondent sample was drawn from frontline service employees in several hospitality organisations in Florida, USA. The human resources managers in each of these organisations made announcements to their employees endorsing the study. The paper-and-pencil surveys were either delivered to the participants or made available in the employee break rooms. A reminder was sent to employees two weeks after the first visit and of the 1,000 surveys distributed, 578 usable responses were returned (58\%). Of the total usable sample, $260(45 \%)$ were male, and $318(55 \%)$ were female. The participants ranged from 18 to 55 years and above, with most in the age group between 18 $25(56 \%)$, followed by the $26-35$ group $(26 \%)$, by $36-55$ group $(12 \%)$, and finally those over $55(4 \%)$. Almost 48 percent of respondents had some college education. Over 65 percent of respondents earned less than $\$ 40,000$ a year, indicative that service employees are paid relatively poorly. The various positions occupied by respondents included bar tenders, bellman, cashier, concierge, front desk agent, server, and sales representative. About one-third of the respondents had been employed by their current organization for three to five years, with $5 \%$ having more than 20 years of experience.

\section{Measures}

$39 E L$

Since the present study involved a survey of hospitality organisations, the research used the Hospitality Emotional Labour Scale (HELS) first 
1 developed by Chu and Murrmann (2006). This scale was developed specifically to measure the EL presentation of hospitality employees and

3 consists of three factors: surface acting, genuine acting and deep acting. To be consistent with two acting strategies of the original EL concept, the two

5 items that were developed to measure genuine acting were excluded for the purposes of the present investigation. Some useful items for measuring

7 surface acting include "I fake the emotions I show when dealing with customers"; "my interactions with customers are very robotic". In the case

9 of deep acting, the sample items are "I work at calling up the feelings I need to show to customers"; "I try to change my actual feelings to match those

11 that I must express to customers". Values were based on a seven-point Likert-type scale with responses ranging from " 1 " (strongly disagree) to " 7 "

13 (strongly agree). Due to the omission of one of the factors from the original HELS, confirmatory factor analysis (CFA) will be performed to confirm the

15 factor structure.

\section{Burnout}

The Maslach Burnout Inventory (MBI) (Maslach \& Jackson, 1986) was used to measure participant burnout. The inventory is a scale consisting of three dimensions, namely emotional exhaustion (9 items), diminished personal accomplishment (7 items), and depersonalisation (6 items). In the case of emotional exhaustion the sample item that was provided is "I feel emotionally drained from my work"; for diminished personal accomplishment "I can't deal effectively with the problems of my recipients"; and for depersonalisation it is "I have become more callous towards people since I took this job". Although its original application was for service workers, the MBI has been applied to other occupations including computer professionals and police officers (see Brotheridge \& Grandey, 2002). It is the most commonly used scale to measure burnout and has been validated by Cordes and Dougherty (1993). In the present study the items were assessed using a seven-point Likert scale $(1=$ strongly disagree, $7=$ strongly agree $)$ to indicate the extent of participant agreement with the statement. The applicable

33 Cronbach alpha coefficients for the three dimensions were .93 in the case of emotional exhaustion, .86 for diminished personal accomplishment, and .82 for depersonalisation.

\section{Emotional intelligence}

39 To determine emotional intelligence, the present study used the self-report EI Test (SREIT) designed by Schutte et al. (1998), which was based on Salovey and Mayer's ability model (1990). The 33-item self-report measure 
1 includes items such as "By looking at their facial expression, I recognize the emotions people are experiencing" and "I easily recognize my emotions as I

3 experience them." Data were collected on a seven-point Likert scale, with $1=$ strongly disagree and $7=$ strongly agree. Higher total scores are reflective

5 of greater self-reported emotional intelligence. Factor analysis of the 33items resulted in one factor representing each of the categories: appraisal

7 and expression of emotion in the self and others, regulation of emotion in the self and others and utilization of emotions in solving problems (Schutt et

9 al., 1998). Petrides and Furnham (2000) have proposed the adoption of a four-factor structure for SREIT. However, the sub-dimensions obtained

11 from CFA in other studies were unstable, and one of the factors had a low Cronbach alpha value (below.70). In light of the incidence of inconsistencies

13 within this scale dimensionality, CFA will be performed and the results and applicable Cronbach alpha coefficient will be reported in the next section.

\section{ANALYSES AND RESULTS}

\section{Factor analyses for SREIT}

21 As indicated above, it was determined that CFA should be conducted for the HELS scale to assess its dimensionalities. The CFA analyses were based

23 on a Pearson Covariance matrix and Maximum Likelihood Estimation (MLE) (Hu \& Bentler, 1999). The results arising from performing CFA

25 for HELS confirmed the two-factor structure as a good model fit $\left(\chi^{2}\right.$ $(561)=217.32, p<.0005, \mathrm{SRMR}=.05$ and $\mathrm{RMSEA}=.05, \mathrm{CFI}=.96$ and

$27 \mathrm{TLI}=.95$ ). As indicated in Table 1 , this item had a significant loading on the corresponding factor.

29 Since the previous research had generated inconsistent results exploratory factor analysis (EFA) was used to identify the factor structures prior to

31 undertaking CFA for SREIT. The results which arose from the conduct of factor analysis for SREIT produced a four-factor structure in the

33 component matrix. However, the other three factors have cross loadings with the first factor, and each loaded only with a single item. Cattell's Scree

35 test indicated that the single factor solution was appropriate, consistent with the result by Schutte et al. (1998). Results from performing CFA also

37 supported the one-factor solution for SREIT, with reasonable model fit indices: $\chi^{2}(571)=1762.34, p<.0005$, SRMR $=.04$ and $\mathrm{RMSEA}=.05$,

$39 \mathrm{CFI}=.98$ and TLI $=.95$. Results from the four-factor solution for SREIT were less optimal. On this basis, the single-factor SREIT was adopted for 
Table 1. CFA results for HELS.

HELS Factors and Items

Loadings

Alpha

Composite

AVE

$5 \quad$ Surface acting

I put on a mask in order to express

Reliability

the right emotions for my job

7 I have to cover up my true feelings

.61

when dealing with customers

9 I display emotions that I am not actually feeling

11 I fake the emotions I show when dealing with customers

3 My interactions with customers are very robotic

I put on an act in order to deal with customers in an appropriate way

I behave in a way that differs from how I really feel

17 I fake a good mood when interacting with customers

19

Deep acting

21 I work at calling up the feelings I need to show to customers

I have to concentrate more on my

23 behaviour when I display an emotion that I don't actually feel

25 I try to talk myself out of feeling what I really feel when helping customers

27 I try to change my actual feelings to match those that I must

29 express to customers

When working with customers,

31 emotions that present the image my company desires

33 Fit statistics:

$\chi^{2}(561)=217.32, p<.0005$,

35 SRMR $=.05$

RMSEA $=.05$

$\mathrm{CFI}=.96$

$\mathrm{TLI}=.95$

Alpha $=$ Cronbach Alpha coefficients, $\mathrm{AVE}=$ average variance extracted 
Table 2. Means, Standard Deviations, Inter-Correlations and Cronbach Alpha Coefficients.

3

5

25 Structural equation modelling was conducted to test the propositions. Following the two-step approach suggested by Anderson and Gerbing 27 (1988), the construct validities were tested prior to testing the proposed relationships between the variables. Because every construct in this study

29 was measured using multiple items, the inclusion of all indicators in the testing would add excessive complexity for the purposes of making accurate

31 estimations. Consistent with the approach recommended by Park and Holloway (2003), the items for each construct were summed into a single

33 indicator measure. The shared variances among these variables do not exceed 40 percent, which indicates that they are empirically distinct

35 constructs, and supports discriminant validity. The coefficients values indicate that all items have a significant loading on their corresponding

37 constructs, demonstrating adequate convergent validity.

To test the hypotheses, the information that arose from the assessment of

39 measurement validity was used to estimate the overall structural model. The errors for each construct were set at .85 (see Williams \& Podsakoff, 1989). 
1 To examine the structural relationships, the proposed main effect model was estimated. The interaction terms were used for testing the moderating effect

3 of emotional intelligence. Lance's (1988) residual centring approach was followed and obtained interaction terms for surface or deep acting.

5 Emotional intelligence was achieved by partialing out the influence of main effects. These interaction terms were then included in the path analysis. The

7 overall goodness-of-fit statistics suggest that the proposed model is acceptable with CFI and TLI values around .95, and SRMR and RMSEA

9 values below 06 .

The results for Hypotheses 1 and 2 are displayed in Table 3. Specifically,

11 both surface acting and deep acting had significant effects on three dimensions of burnout: the beta values for surface/deep acting - emotional

13 exhaustion are $.39(p<.0005)$ and $.08(p<.05), .11(p<.05)$ and .12 $(p<.0005)$ for surface/deep acting - diminished personal accomplishment,

15 and $.37(p<.0005)$ and $.14(p<.005)$ for surface/deep acting - depersonalisation. These results indicate that $\mathrm{H} 1$ was confirmed.

17 The analyses of the moderating effect of emotional intelligence generated mixed results (as displayed in Table3) for H2. Specifically, emotional intelli-

19 gence significantly reduced the levels of surface/deep acting - emotional exhaustion $(\beta=-.36, p<.0005 ; \beta=-.18, p<.05)$, surface/deep acting -

21 diminished personal achievement $(\beta=-.16, p<.0005 ; \beta=-.09, p<.05)$,

Table 3. The Relationships Between EL and Burnout, and The Moderating Effect of EI on EL and Burnout.

\begin{tabular}{lllclcc}
\hline Variables & $\mathrm{EE}(\beta)$ & $\Delta \mathrm{R}^{2}$ & $\mathrm{DPA}(\beta)$ & $\Delta \mathrm{R}^{2}$ & $\mathrm{DP}(\beta)$ & $\mathrm{R}^{2}$ \\
\hline & & $.15^{* * *}$ & & $.05^{* * *}$ & & $.15^{* * *}$ \\
SA & $.39^{* * *}$ & & $.11^{*}$ & & $.37^{* * *}$ & \\
DA & $.08^{*}$ & & $12^{* * *}$ & & $.14^{* *}$ & \\
SA*EI &.$-36^{* * *}$ & $.11^{* * *}$ & $-.16^{* * *}$ & $.07^{* * *}$ & $-.19^{* * *}$ & $.08^{* * *}$ \\
DA*EI & $-.18^{* * *}$ & $.06^{* * *}$ & $-.09^{*}$ & .00 & $.19^{* * *}$ & $.08^{* * *}$
\end{tabular}

33 Overall model fit statistics for the analyses $\chi^{2}$

35 CFI

TLI

SRMR 
1 surface/deep acting - depersonalisation $(\beta=-.19, \mathrm{p}<.0005 ; \beta=-.19$, $\mathrm{p}<.0005)$.

\section{DISCUSSION}

7 This study has examined the relationships between EL and three dimensions of burnout. Emotional intelligence was proposed as a potential moderator

9 in EL strategy. The testing from structural equation modelling yielded some interesting results. Conforming to $\mathrm{H} 1$, both surface and deep acting were

11 strongly associated with all dimensions of burnout. The testing of moderation has shown that emotional intelligence reduced the levels of

13 burnout (all three dimensions) through surface or deep acting. Discussion of these findings is as follows.

EL and burnout

19 As predicted, surface and deep acting related positively to all three dimensions of burnout. Although some studies have reported that only

21 surface acting is related to burnout, this finding supported Ashforth and Humphrey's (1993) proposition and the finding of and Mikolajczak et al.'s

23 (2007) study. The inconsistency may lie in the different sampling frames. The present investigation focused on hospitality service employees. Given

25 the intensifying competition in recent years and organizational restructuring in the industry, these service employees face the threat of retrenchment as

27 well as excessive job demands (see Lo \& Lamm, 2005). In order to keep their jobs, they have to follow organizational rules to "act". Lack of spontaneity

29 and unwillingness in their acting may eventually lead to job dissatisfaction and burnout (Brotheridge \& Grandey, 2002; Pugliesi, 1999). If these

31 employees perceive it as necessary to act genuinely (deep acting) but are unable or unwilling to do so (due to low wage), they may suffer low self-

33 esteem or self-alienation, eventually leading to burnout. The current study provides new insights into deep acting strategies and suggests that

35 researchers should be cautious about promoting deep acting. This finding is consistent with Ashforth and Humphrey's argument that EL is

37 dysfunctional and that ultimately "deep acting may ultimately lead to self-alienation ... the masking or reworking of authentic emotions that one

39 would otherwise prefer to express has been linked to psychological and physical dysfunctions (see Ashforth \& Humphrey, 1993, p 97). 
3 The results from the moderation analyses indicate that the incorporation of moderator can be a remedy for reducing EL-caused burnout. Emotional

5 intelligence successfully moderated the relationship between the two EL acting processes and burnout. This finding is consistent with the Daus and

7 Ashkenasy (2005) assertion that emotional intelligence plays a significant role in jobs which demand high EL such as customer service representative. The

9 service encounter between employees and customers often involves a strong emotional component due to unpredictable situational factors and demand-

11 ing customers (see Ashforth \& Humphrey, 1993). Employee emotional intelligence may facilitate service transactions through managing the

13 emotions of oneself or others. Smooth transactions lead to fewer customer complaints and therefore less employee stress. Stress is a precursor of

15 burnout.

\section{Theoretical Implications and future research}

19

39 In the context of the present study, the capacity of emotional intelligence has
been shown as a means of reducing burnout acquired through acting. Since

39 In the context of the present study, the capacity of emotional intelligence has
been shown as a means of reducing burnout acquired through acting. Since

This study has provided a contribution to the EL and emotional intelligence literature. Firstly, the finding that there is a positive relationship between deep acting and burnout should alert EL researchers of the need to deepen their understanding of genuine acting or reassess its consequences. Equally, researchers should take account of the study population as a possible case of inconsistent findings. Future studies should test this relationship in different contexts with a view to verifying the findings. Secondly, the significant moderating effect exhibited by emotional intelligence in the EL-burnout relationship supports Grandey's (2000) proposition and extends its moderation role into the EL process. It is notable that the use of an onefactor solution for the emotional intelligence measure in this study has resulted in better model fit indices when undertaking CFA. The result of the single-factor emotional intelligence also conforms to Schutte et al.'s (1998) study. The findings are a reminder to researchers about the importance of undertaking a factor-analysis of these measures before undertaking further analysis. 
1 it is trainable and developable (see Boyatzis, Cowan, \& Kolb, 1995; Slaski \& Cartwright, 2002), relevant training should be provided for existing frontline

3 employees, particularly in the case of those who perform emotional labour but are unable to act appropriately. It is evident that possession of a high

5 level of emotional intelligence can reduce the likelihood of burnout and may improve performance. As indicated in the literature, service employee 7 performance has implications for customer satisfaction and loyalty. Emotional intelligence testing can also be used for recruitment and selection

9 purposes. The conduct of such testing could help human source managers in identifying suitable candidates.

15 Ashkanasy, Ashton-James, and Jordan (2004); Boyatzis, Cowen, and Kolb (1995); Jordan, Ashkanasy, and Härtel (2003); Mikolajczak and 17 Clemeentine (2007); Montgomery, Panagopolou, and Meenks (2006); Organ (1988).

\section{REFERENCES}

Anderson, J. C., \& Gerbing, D. W. (1988). Structural equation modelling in practice: A review and recommended two-step approach. Psychological Bulletin, 103(3), 411-423. doi: 10.1037/0033-2909.103.3.411

Ashforth, B. E., \& Humphrey, R. H. (1993). Emotional labor in service roles: The influence of identity. Academy of Management Review, 18(1), 88-115.

Ashkanasy, N. M, Ashton-James, E., \& Jordan, J. (2004). Performance impacts of appraisal and coping with stress in the workplace settings: The role of affect and emotional intelligence'. In P. L. Perrewe, \& D. C. Ganster (Eds.), Emotional and psychological processes and positive intervention strategies, 3. (pp. 1-13).

Boyatzis, R. E., Cowen, S. S., \& Kolb, D. A. (1995). Innovation in professional education: Steps on a journey from teaching to learning: Jossey-Bass.

Brotheridge, C. M., \& Grandey, A. (2002). Emotional labor and burnout: Comparing two perspectives of. Journal of Vocational Behavior, 60(1), 17-39.

Chu, K. H., \& Murrmann, S. K. (2006). Development and validation of the hospitality emotional labor scale. Journal of Hospitality \& Tourism Research, 27(6), 1181-1191.

Cordes, L., \& Dougherty, W. (1993). A review and an integration of research on burnout. Academy of Management review, 18, 621-656.

Daus, C. S., \& Ashkanasy, N. M. (2005). The case for the ability-based model of emotional intelligence in organizational behaviour. Journal of Organizational Behaviour, $26,453-466$. 
1 Douglas, C., Frink, D., \& Ferris, R. (2004). Emotional intelligence as a moderator of the conscientiousness-performance relationship. Journal of Leadership \& Organizational Studies, 10, 2-13.

Erickson, J., \& Ritter, C. (2001). Emotional labor, burnout, and inauthenticity: Does gender matter? Social Psychology Quarterly, 64(2), 146-163.

Fineman, S. (1993). Organizations as emotional arenas. Emotions in Organisations. Thousand Oaks, CA, USA: Sage Publications. In Fineman, Stephen (Ed). Xiii, 230pp

7 Gabbott, M., Tsarenko, Y., \& Mok, W. H. (2011). Emotional intelligence as a moderator of coping strategies and service outcomes in circumstances of service failure. Journal of Service Research, 14(2), 234-248.

Grandey, A. (2003). When "the show must go on": Surface acting and deep acting as determinants of emotional exhaustion and peer-rated service delivery. Academy of Management Journal, 46(1), 86-96.

Hochschild, A. R. (1983). The managed heart. Berkeley, CA: University of California Press.

Johnson, M., \& Spector, E. (2007). Service with a smile: Do emotional intelligence, gender, and autonomy moderate the emotional labor process? Journal of Occupational Health Psychology, 12(4), 319.

$15 \mathrm{Hu}, \&$ Bentler. (1999). Cutoff criteria for fit indexes in covariance structure analysis: Coventional criteria versus new alternatives. Structural Equation Modelling, 6(1), 1-55.

Jordan, P. J., Ashkanasy, N. M., \& Härtel, C. E. J. (2003). The case for emotional intelligence in organizational research. Academy of Management Review, 28(2), 195-197.

Kim, H. J. (2008). Hotel service providers' emotional labor: The antecedents and effects on burnout. International Journal of Hospitality Management, 27(2), 151-161.

Lance, E. (1988). Residual centering, exploratory and confirmatory moderator analysis, and decomposition of effects in path models containing interactions. Applied Psychological Measurement, 12(June), 163-175.

Levine, R. (1997). Financial development and economic growth: Views and agenda. Journal of economic literature, 35(2), 688-726.

Lo, K., \& Lamm, F. (2005). Occupational stress in the hospitality industry - an employment relations perspective. Hospitality Stress. http://library.auckland.ac.nz/subject-guides/ bus/docs/loandlamm.pdf

27 Mann, S., \& Cowburn, J. (2005). Emotional labour and stress within mental health nursing. Journal of Psychiatric and Mental Health Nursing, 12(2), 154-162.

Maslach, C., \& Jackson, S. (1986). Maslach burnout inventory. Evaluating Stress a book of resources, 31, 191-218.

Mayer, D., \& Salovey, P. (1997). What is emotional intelligence? In P. Salovey \& D. Sluyter (Eds.), Emotional development and emotional intelligence: Implications for educators (pp. 3-31). New York: Basic Books.

Mayer, D., Salovey, P., Caruso, D. R., \& Sitarenios, G. (2001). Emotional intelligence as a standard intelligence. Emotions, 1, 232-242.

Mikolajezak, M. M., \& Clemeentine, L. (2007). Explaining the protective effect of trait emotional intelligence regarding occupational stress: Exploration of emotional labour process. Journal of Research in Personality, 41(2007), 1107-1117.

Montgomery, A. J., Panagopolou, E., \& Meenks, E. (2006). Work-family interference, emotional labor and burnout. Journal of Managerial Psychology, 21(1), 36-51. 
1 Nunnally, J. C., \& Bernstein, I. H. (1994). Psychometric theory. New York: McGraw.

Organ, D. W. (1988). Organizational citizenship behavior: The good soldier syndrome. Lexington Books/DC Heath and Com.

Park, J. E., \& Holloway, B. B. (2003). Adaptive selling behaviour revisited: An empirical examination of learning orientation, sales performance, and job satisfaction. Journal of Personal Selling \& Sales Management, XXIII(3), 239-251.

Parkinson, B. (1991). Emotional stylists: Strategies of expressive management among trainee hairdressers. Cognition and Emotion, 5, 419-434.

Petrides, K., \& Furnham, A. (2000). On the dimensional structure of emotional intelligence. Personality and Individual Differences, 29(2), 313-320.

Pugliesi, K. (1999). The consequences of emotional labor: Effects on work stress, job satisfaction, and well-being. Motivation and Emotion, 23(2), 125-154.

11 Rutter, D. R., \& Fielding, P. J. (1988). Sources of occupational stress: An examination of British prison officers. Work \& Stress, 2, 291-299.

13 Salami, S. O. (2007). Moderating Effect of emotional intelligence on the relationship between emotional labour and organizational citizenship behaviour. European Journal of Social Sciences, 5(2), 142-150.

15 Schutte, N. S., Malouff, J. M., Hall, L. E., Haggerty, D. J., Cooper, J. T., Golden, C. J., \& Dornheim, L. (1998). Development and validation of a measure of emotional intelligence. Personality and Individual Differences, 25(2), 167-177.

Seeman, N. C. (1991). Construction of three-dimensional stick figures from branched DNA.

DNA and cell biology, 10(7), 475-486.
19 Slaski, M., \& Cartwright, S. (2002). Health, performance and emotional intelligence: An exploratory study of retail managers. Stress and Health, 18(2), 63-68.

21 Surana, S., \& Singh, A. K. (2009). Development and validation of job burnout scale in the Indian context. International Journal of Society Systems Science, 1(4), 351-374.

23 Williams, L. J., \& Podsakoff, P. M. (1989). Longitudinal field methods for studying reciprocal relationships in organizational behavior: Toward improved causal analysis. In B. M. Staw \& L. L. Cummings (Eds.), Research in organizational behavior (Vol. 2, pp. 247-292). Greenwich, CT: JAI. 